\title{
Analysis of Parameters and Time Sequences for Full Operation Mode of Vacuum Interrupter for Medium Voltage Power Plants
}

\author{
Shaker Jassem Gatan \\ Department of Power Electrical Engineering, Riga Technical University, Riga, Latvia
}

Email address:

Shaker.gatan@outlook.com

\section{To cite this article:}

Shaker Jassem Gatan. Analysis of Parameters and Time Sequences for Full Operation Mode of Vacuum Interrupter for Medium Voltage Power Plants. American Journal of Information Science and Technology. Vol. 2, No. 2, 2018, pp. 57-63. doi: 10.11648/j.ajist.20180202.15

Received: April 23, 2018; Accepted: June 14, 2018; Published: July 24, 2018

\begin{abstract}
Parameters of a vacuum interrupter are essential. Although most of researchers and industries are involving metallurgy by using a refractory materials "alloys" electroplates for vacuum interrupter for the sake of sustainable materials against both arcing current, chopping currents and disruptive over voltages. This paper addresses the description of all parameters and evaluates switching processing times for three circuit breakers, VD4 /ABB Vacuum type 6.6KV/1500A/20KV/40KV-IEC60-071 for maximum switching times 2.7ms." Three synchronous generators $6.6 \mathrm{KV} / 8 \mathrm{MW}$ each have been connected to three power transformers, rating $6.6 \mathrm{KV} / 1250 \mathrm{KVA}$ in refinery power plant.
\end{abstract}

Keywords: Parameters of Switching Processing Times, Alculating Chopping Currents, Sequences of Switching Process

\section{Introduction}

Since many years up to date now, we are still constructing the vacuum circuit breaker by classical design, but the interacting among the characteristics inside each vacuum interrupter must be scientifically analysis as a high values of the general specification which must be thoroughly understood before the breaker can be applied with safety confidence. Moreover the switching process associated with power electronics offers many modern benefits as a static switching system when joints together by using a snubber circuits for damping chopping current and transient over voltages or other facilities [1-16].

This paper focuses on the understanding of both characteristics and load specification relative to vacuum circuit breaker to generate precisely parameters [1-12]. Circuit switching system - electroplates including some devices utilizing vacuum interrupters have been viewed as eliminating both of switching surge, arcing currents and high frequency rates for any interval times (microseconds Process). In addition the inside electroplates some characteristics can be described as followings:

1. Time of arcing current

2. Time of chopping current

3. Time of Prestrike transient over- voltages
4. The value of restrikes over voltages

5. Multiple re-ignitions

6. Time of voltage escalation $\&$ frequencies

7. Non-sustained disruptive discharge voltages

In general, the above characteristics are not involving associated with only vacuum switchgear itself a lone, but when connects the switchgear with power distribution transforms or synchronous motors, there are also many negative interactive processes for instance hysteresis currents, eddy currents and high voltage capacitive inside each transformer (Parasites electrostatics charged) feedback to the interrupter process.

\section{Switching Process}

Since the vacuum arc is the key element in the vacuum interrupter, some knowledge of its structure and behavior is essential for understanding the operation of vacuum switching process. The name vacuum arc is really incorrect, indeed, it's a contradiction [2] "If there is a vacuum there is no arc, and if there is an arc there is no vacuum". A more exact name would be metal vapor arc inside vacuum electroplate.

$$
J=(A T)^{2} * e^{-\emptyset k T}
$$




$$
\mathrm{J}=2 * 10^{6}\left(\mathrm{~A} / \mathrm{m}^{2}\right)
$$

Joule heating as thermionic emission Where $\varnothing$ is the thermionic work function. $K$ is Boltzmann's constant $(1.37 \times 10-23$ Joules $/ K)$ The constant $A$ is approximately $6 \times 10^{5}$ for most metals 1. Time of arcing current According to the Harris model and classification who was classified "the positive ions initiated from ionization process in an Anode plate and generates joule heating to a cathode plate surface during switching process";

i. Ionization zone

ii. Acceleration zone

iii. The total above processing time was measured by Harris approximately $(20-250 \mu \mathrm{s})$ [15].

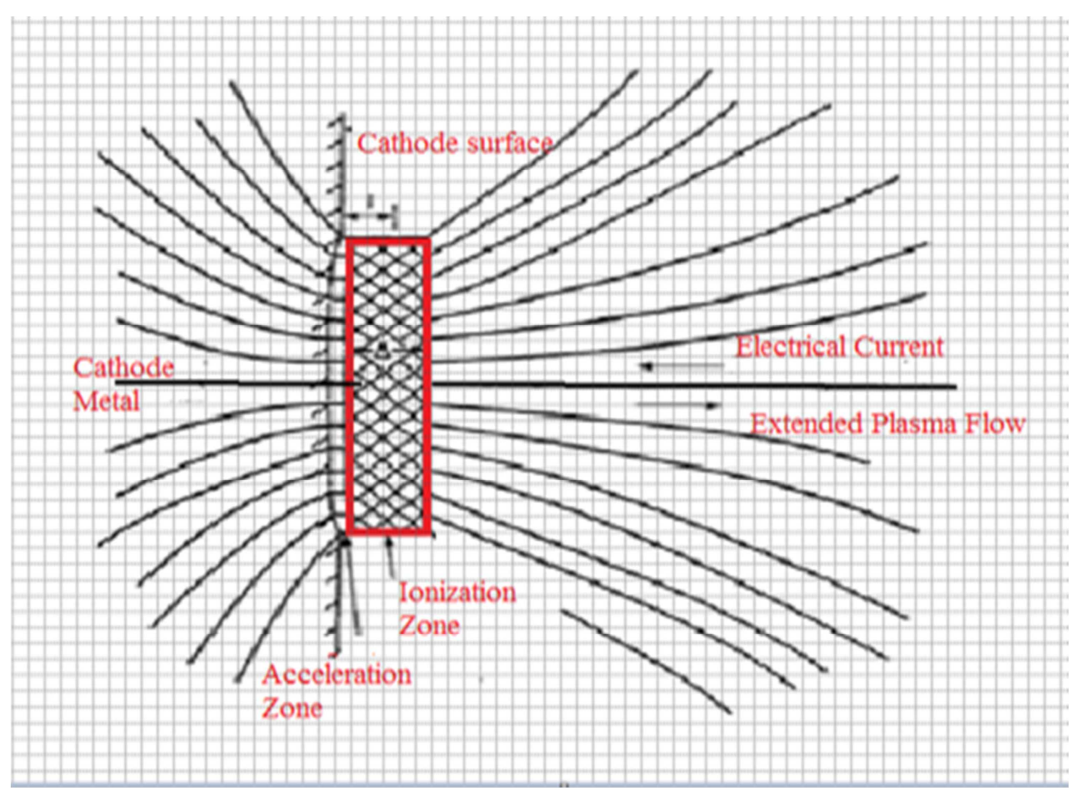

Figure 1. Cathode cell geometry and potential distribution in Harris model.

\section{Time of chopping current}

Current chopping refers to the prospective over voltage events which can result with certain types of inductive load (power transformer) due to the premature suppression of the power frequency current before normal current zero in the vacuum interrupter.

The term multiple re-ignitions refers to the series of alternate re-ignitions and high frequency (typical several hundred $\mathrm{KHz}$ )interruptions usually resulting in an increasing train of voltage peaks; this overall phenomena is usually defined as voltage escalation $[3,4]$.

If the high frequency accompanying re-ignitions and voltage escalation in one phase couple into other two phases, the process of virtual current chopping can occur [6]. Virtual current chopping involves the load current in the other two phases being forced to zero by superimposed high frequency re ignition coupled current. It is important to appreciate that while current chopping and voltage escalation can occur in a single -phase circuit, virtual current chopping is specifically a 3-phase characteristic: the effects of normal current chopping, multiple re ignition and over voltage escalation in one phase can generate surge over voltages in the second and third phases.

3. Time of Prestrike transient over-voltages

Pre-striking of the breaker in picking up a transformer load is somewhat similar to the multiple re-ignition event which occurs on opening a breaker [7]. A high frequency current governed by the circuit parameters flows. However pre- striking transient over voltages is less severe than multiple re-ignitions occurring during load- dropping, first because the contact gap at the first prestrike is very small and second because the contact gap is rapidly decreasing rather than increasing with respect of time.

4. The restrikes over voltages

Restrike overvoltage due to the multiple re-ignition of circuit breaker when a switching interrupter process is initiated before current zero.

\section{Multiple re-ignitions}

Multiple repeated ignitions mean an over voltage magnitude is a straightforward concept: as the amplitude of any overvoltage increases, the probability of breakdown in vacuum or breakdown of solid insulation increases. Consequently, overvoltage magnitude must be considered

Transient voltage rate-of -rise is important because very fast rising transients can cause the over voltage to be nonuniformly distributed the transformer windings. For example, a voltage transient with $0.2 \mu \mathrm{s}$ rise time may result in $80 \%$ to $100 \%$ of a voltage surge appearing across the first coil of the above each transformer for multi-coil windings, turns of the first coil could be 6 time higher if the transient was slow rising for each $0.2 \mu \mathrm{s}$ impulses Consequently this magnitude is well below of the transformer windings could damage the inter-trun insulation of the fist coil of the winding.

An important factor to consider is that, even if the nonuniform voltage distribution in a winding does not actually result in a failure of the inter-turn insulation, respectively, the 
fast-rising transients can gradually degrade insulation to the possible point of failure over long period of time- many years over age for power transformers.

The multiple re-ignition phenomena can cause winding insulation to be subjected to fast -transients more frequently with vacuum switchgear (several times per switching event) than with other types of switchgears. It is therefore, important $t$ determine those applications where fast transients could be cause problems, and to take appropriate measures to control the voltage rate-of-rise for this application.

6. Repeated high frequencies inside interrupter

a) The first of these is $50 \mathrm{~Hz}$.

b) The second frequency is the normal frequency load transient recovery voltage, normally in the range from $(500 \mathrm{~Hz}$ to $5 \mathrm{KHz})$. This normal recovery voltage frequency is governed by the effective inductance of the load and capacitance from load terminal to ground; this capacitance may have three components- terminal bushing to ground capacitors, cable capacitors, and a surge capacitors if one is provide at the load the sequence time feedback to the circuit will in the range of between $(100 u s-250 u s)$.

c) The third frequency is that due to high frequency reignitions. Note that in all systems, irrespective of what type of breaker is used, high frequency currents are caused to flow whenever the breaker reignites of prestrikes. The value of frequency is determined by the effective capacitance at the load and the effective inductance of the cable between breaker and load When a re-ignition, restrike, or prestrike transient over voltages occur in the circuit switching device, the collapse of a voltage surge into cable -load system This surge is reflected at the load terminal, returns to the source- breaker end of the system, and travels back and forth along the cable many times until attenuated by losses. The frequency of the current is related to the travel/return frequency of reflected surges propagated back and forth along cable; the frequency is directly proportional to cable length, modified by resistive and reflective attenuation losses. Typical values of high frequency of high frequency vary in the range over $2 \mathrm{MHz}$ for $100 \mathrm{~m}$ /length of cable given $0.2 \mathrm{us}$ rise-oftime, to over $50 \mathrm{KHz}$ for $5000 \mathrm{~m} /$ length of cable with almost between (12-25 $\mu$ sec rise-of-time) non valuable.

\section{Chopping Currents Calculation}

The process of current chopping is the premature suppression of $50 \mathrm{~Hz}$ or $60 \mathrm{~Hz}$ circuit current before normal current zero due to instability of the arcs in a vacuum interrupter [6-7]. Although the current in the vacuum interrupter can chop to zero almost instantaneously (fraction of a microsecond), the current in the load inductance- $3 \mathrm{ph}$ coils in the power transformer cannot attain zero value instantaneously. Time is required for magnetic energy to be transferred from the inductance "transform inductance loads", and for the magnetic field associated with stored energy to collapse.

When current chop occurs, the energy stored in the effective load inductance is transferred to the available loadside capacitance to produce the so called chop overvoltage, given by $\mathrm{Ic} \sqrt{ }(1-\gamma) \mathrm{L}_{\mathrm{b}} / \mathrm{C}_{\mathrm{s}}$ where $I c$ called chopping current level and $\sqrt{ } \mathrm{L}_{\mathrm{b}} / \mathrm{C}_{\mathrm{s}}$ ionization of medium voltage impedance; $\gamma$ represents circuit losses generate joule heating and lightning impulse, especially ions loss and very significant in limiting chop overvoltage[5][6]. For determine the actual value of first peak of chopping current.

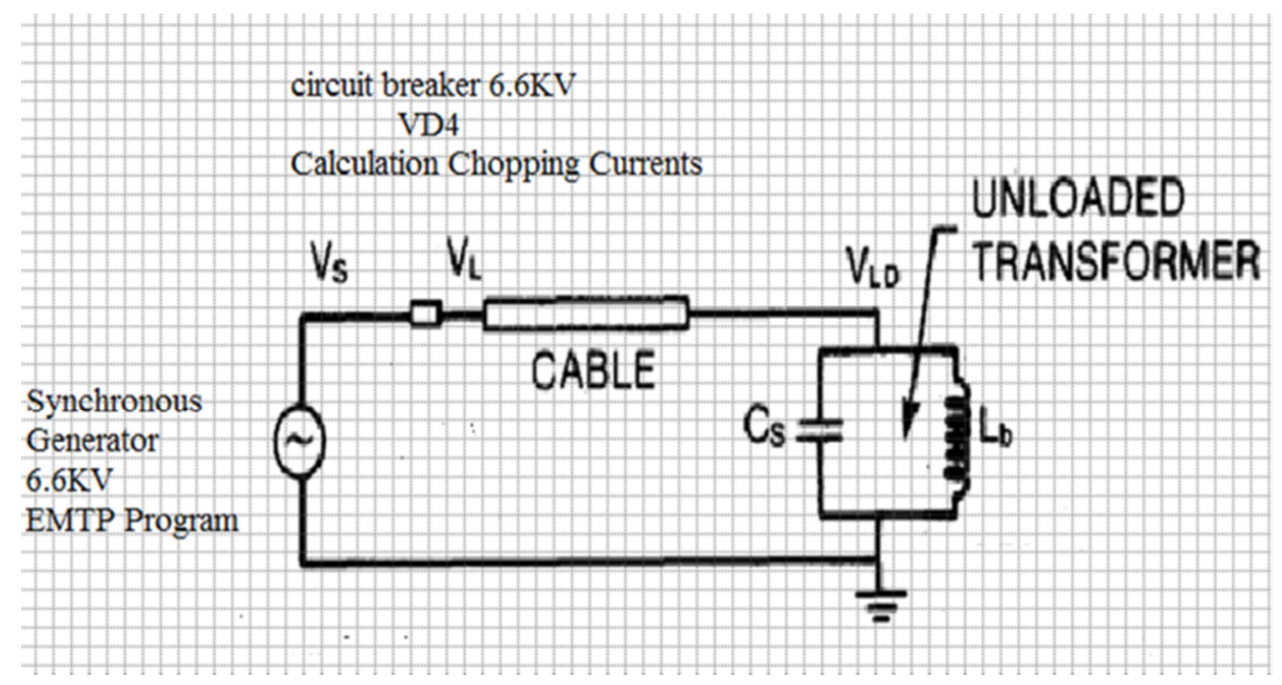

Figure 2. Capacitive condensers surge phenomena.

$$
V_{T}=I_{c} * Z_{\text {Load }}
$$

$\mathrm{Vt}$ - Voltage Transient

Ic - Current Chop, First peak value

Z load - Load Impedance
$\mathrm{U}$ - Operating Voltage of inductance Load- KV

Ur- Rated Voltage - maximum RMS -KV

$\mathrm{U}_{\mathrm{d}}$ - Insulation Level- Rated power frequency RMS-KV

Up- Rated Lightning Impulse withstand level $-\mathrm{KV}$; 1.2/50us withstand level of IEEE 


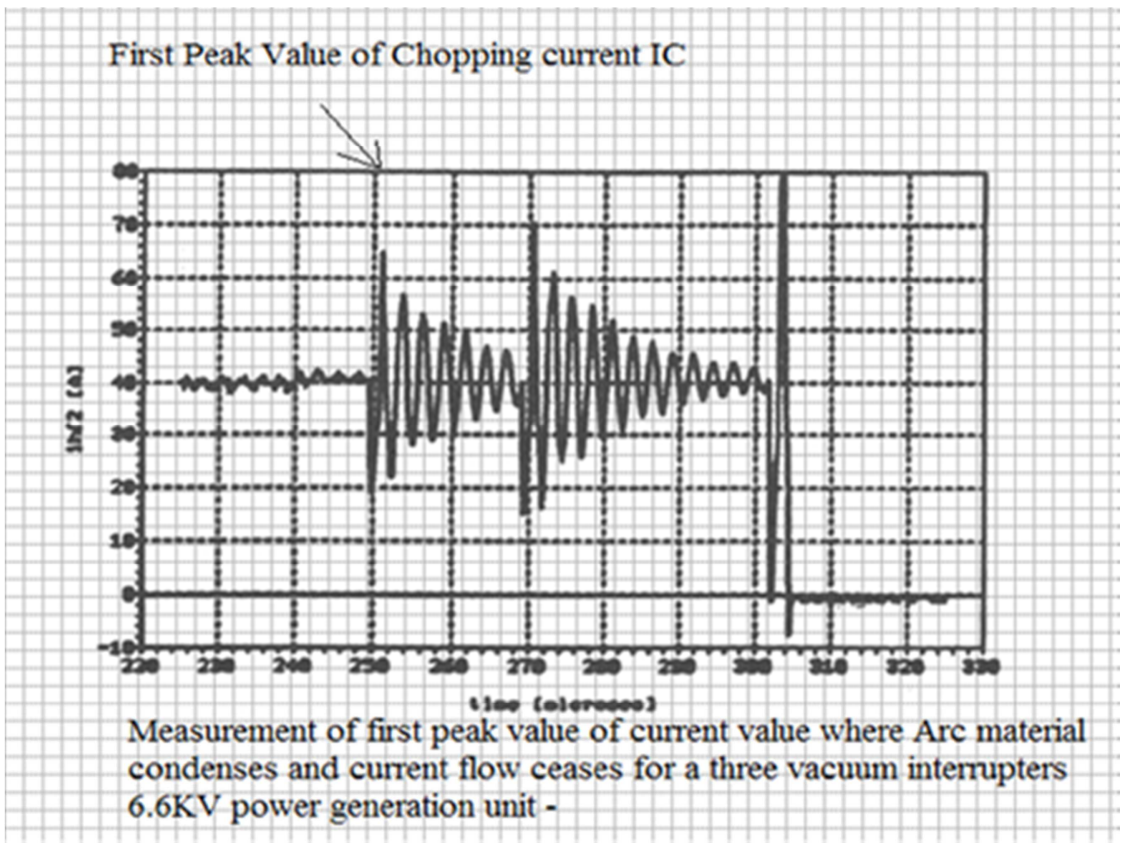

Figure 3. Chopping current characteristics.

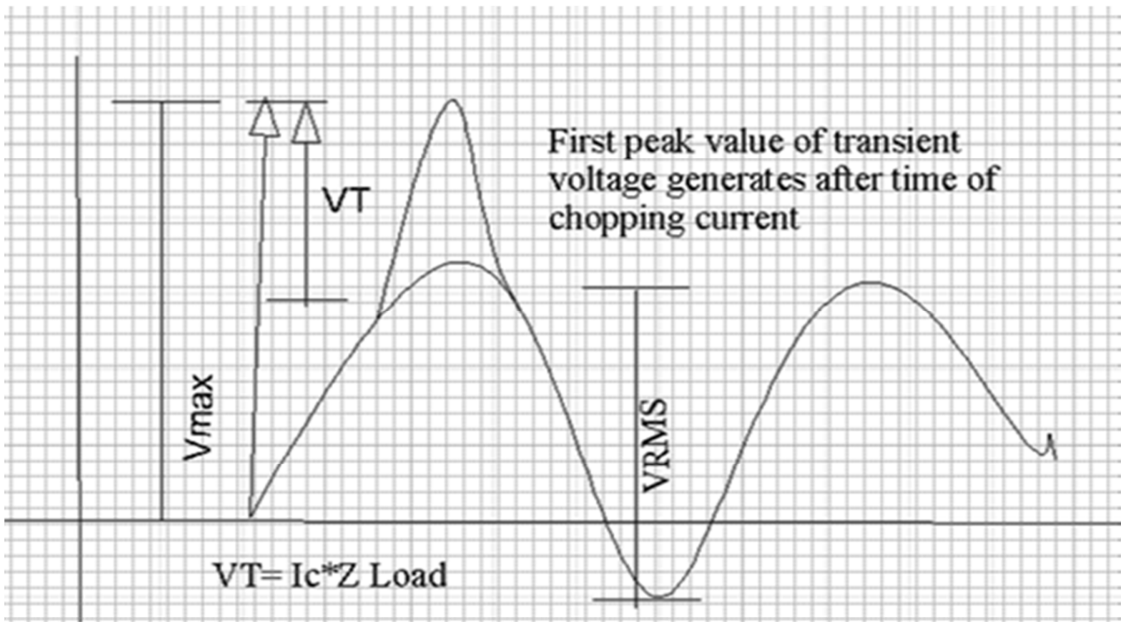

First peak value combines with voltage parameters $=$ TRV

Figure 4. First peak value of transient over voltage.

According to the equation (1) above;

$=0.5 \mathrm{~A} * 3000 \Omega=1500$ volt

$\mathrm{V}_{\text {Max }}=\mathrm{V}_{\mathrm{RMS}}+\mathrm{V}_{\mathrm{t}}=1.5+7.5=9 \mathrm{KV}$

This is a first calculation which is acceptable value for the first peak value of transient over voltage

$\mathrm{N}$ : B the rating of the synchronous is Followings

$\mathrm{U}=6.6 \mathrm{KV}$

$\mathrm{U}_{\mathrm{r}}=7.2 \mathrm{KV}-\mathrm{RMS}-\mathrm{KV}$

$\mathrm{U}_{\mathrm{d}}=20 \mathrm{KV}$ - Maximum withstand level of Insulation

So, from the table I that we can assume the maximum value of chopping current cannot be exceed above $6 \mathrm{~A}$ for the reason of disruptive over voltages.
Table 1. First table calculation at $Z=3000 \Omega$.

\begin{tabular}{llll}
\hline Ic & $\mathbf{U}_{\text {MAX }}$ & $\mathbf{U}_{\mathbf{d}}$ & Max Rated level \\
\hline $0.5 \mathrm{~A}$ & $9 \mathrm{KV}$ & $20 \mathrm{KV}$ & Acceptable IEC standard \\
$0.7 \mathrm{~A}$ & $9.3 \mathrm{KV}$ & $20 \mathrm{KV}$ & Acceptable IEC standard \\
$0.75 \mathrm{~A}$ & $9.45 \mathrm{KV}$ & $20 \mathrm{KV}$ & Acceptable IEC standard \\
$0.8 \mathrm{~A}$ & $9.6 \mathrm{KV}$ & $20 \mathrm{KV}$ & Acceptable IEC standard \\
$0.9 \mathrm{~A}$ & $9.9 \mathrm{KV}$ & $20 \mathrm{KV}$ & Acceptable IEC standard \\
$1 \mathrm{~A}$ & $10.2 \mathrm{KV}$ & $20 \mathrm{KV}$ & Acceptable IEC standard \\
$2 \mathrm{~A}$ & $13.2 \mathrm{KV}$ & $20 \mathrm{KV}$ & Acceptable IEC standard \\
$3 \mathrm{~A}$ & $16.2 \mathrm{KV}$ & $20 \mathrm{KV}$ & Acceptable IEC standard \\
$5 \mathrm{~A}$ & $22.2 \mathrm{KV}$ & $20 \mathrm{KV}$ & Acceptable IEC standard \\
$6 \mathrm{~A}$ & $25.2 \mathrm{KV}$ & $20 \mathrm{KV}$ & Not Acceptable \\
$10 \mathrm{~A}$ & $37.2 \mathrm{KV}$ & $20 \mathrm{KV}$ & NDD- Disruptive \\
$11 \mathrm{~A}$ & $40.2 \mathrm{KV}$ & $20 \mathrm{KV}$ & NDD- Disruptive \\
$12 \mathrm{~A}$ & $43.2 \mathrm{KV}$ & $20 \mathrm{KV}$ & NDD-Disruptive \\
\hline
\end{tabular}


Table2. Second table calculation at $Z=5000 \Omega$.

\begin{tabular}{llll}
\hline Ic & & $\mathbf{U}_{\mathbf{d}}$ & Max Rated level \\
\hline $0.5 \mathrm{~A}$ & $10.2 \mathrm{KV}$ & $20 \mathrm{KV}$ & Acceptable IEC standard \\
$0.7 \mathrm{~A}$ & $11.4 \mathrm{KV}$ & $20 \mathrm{KV}$ & Acceptable IEC standard \\
$0.75 \mathrm{~A}$ & $11.7 \mathrm{KV}$ & $20 \mathrm{KV}$ & Acceptable IEC standard \\
$0.8 \mathrm{~A}$ & $12 \mathrm{KV}$ & $20 \mathrm{KV}$ & Acceptable IEC standard \\
$0.9 \mathrm{~A}$ & $12.6 \mathrm{KV}$ & $20 \mathrm{KV}$ & Acceptable IEC standard \\
$1 \mathrm{~A}$ & $13.2 \mathrm{KV}$ & $20 \mathrm{KV}$ & Acceptable IEC standard \\
$2 \mathrm{~A}$ & $19.2 \mathrm{KV}$ & $20 \mathrm{KV}$ & Acceptable IEC standard \\
$3 \mathrm{~A}$ & $25.2 \mathrm{KV}$ & $20 \mathrm{KV}$ & Critical \\
$5 \mathrm{~A}$ & $37.2 \mathrm{KV}$ & $20 \mathrm{KV}$ & NDD-Disruptive \\
$6 \mathrm{~A}$ & $43.2 \mathrm{KV}$ & $20 \mathrm{KV}$ & NDD-Disruptive \\
$10 \mathrm{~A}$ & $67.2 \mathrm{KV}$ & $20 \mathrm{KV}$ & NDD-Disruptive \\
$11 \mathrm{~A}$ & $73.2 \mathrm{KV}$ & $20 \mathrm{KV}$ & NDD-Disruptive \\
$12 \mathrm{~A}$ & $79.2 \mathrm{KV}$ & $20 \mathrm{KV}$ & NDD-Disruptive \\
$13 \mathrm{~A}$ & $85.2 \mathrm{KV}$ & $20 \mathrm{KV}$ & NDD-Disruptive \\
\hline
\end{tabular}

Analysis the second table indicates that a critical value of $\mathrm{IC}$ at $3 \mathrm{~A}$ or $5 \mathrm{~A}$ of chopping current.

Table 3. Third table calculation at $Z=6000$.

\begin{tabular}{llll}
\hline Ic & $\mathbf{U}_{\text {MAX }}$ & $\mathbf{U}_{\mathbf{d}}$ & Max Rated level \\
\hline $0.5 \mathrm{~A}$ & $10.2 \mathrm{KV}$ & $20 \mathrm{KV}$ & Acceptable IEC standard \\
$0.7 \mathrm{~A}$ & $11.4 \mathrm{KV}$ & $20 \mathrm{KV}$ & Acceptable IEC standard \\
$0.75 \mathrm{~A}$ & $11.7 \mathrm{KV}$ & $20 \mathrm{KV}$ & Acceptable IEC standard \\
$0.8 \mathrm{~A}$ & $12 \mathrm{KV}$ & $20 \mathrm{KV}$ & Acceptable IEC standard \\
\hline
\end{tabular}

\begin{tabular}{llll}
\hline Ic & $\mathbf{U}_{\text {MAX }}$ & $\mathbf{U}_{\mathbf{d}}$ & Max Rated level \\
\hline $0.9 \mathrm{~A}$ & $12.6 \mathrm{KV}$ & $20 \mathrm{KV}$ & Acceptable IEC standard \\
$1 \mathrm{~A}$ & $13.2 \mathrm{KV}$ & $20 \mathrm{KV}$ & Acceptable IEC standard \\
$2 \mathrm{~A}$ & $19.2 \mathrm{KV}$ & $20 \mathrm{KV}$ & Acceptable IEC standard \\
$3 \mathrm{~A}$ & $25.2 \mathrm{KV}$ & $20 \mathrm{KV}$ & Critical \\
$5 \mathrm{~A}$ & $37.2 \mathrm{KV}$ & $20 \mathrm{KV}$ & NDD-Disruptive \\
$6 \mathrm{~A}$ & $43.2 \mathrm{KV}$ & $20 \mathrm{KV}$ & NDD-Disruptive \\
$10 \mathrm{~A}$ & $67.2 \mathrm{KV}$ & $20 \mathrm{KV}$ & NDD-Disruptive \\
$11 \mathrm{~A}$ & $73.2 \mathrm{KV}$ & $20 \mathrm{KV}$ & NDD-Disruptive \\
$12 \mathrm{~A}$ & $79.2 \mathrm{KV}$ & $20 \mathrm{KV}$ & NDD-Disruptive \\
$13 \mathrm{~A}$ & $85.2 \mathrm{KV}$ & $20 \mathrm{KV}$ & NDD-Disruptive \\
\hline
\end{tabular}

\section{Switching Transient Calculation}

EMTP which is called electromagnetic transient program or others such as SIMULINK/MATLAB are excellent numerical tools that allow for depth studies of switching transients in industrial as well as utility power systems. Since the high frequency characteristics of the power system equipment are depend on stray capacitances that mentioned above and inductances also and they in turn depend on physical dimensions, equipment layout, materials, cable lengths, all these can be represented as follows [17];

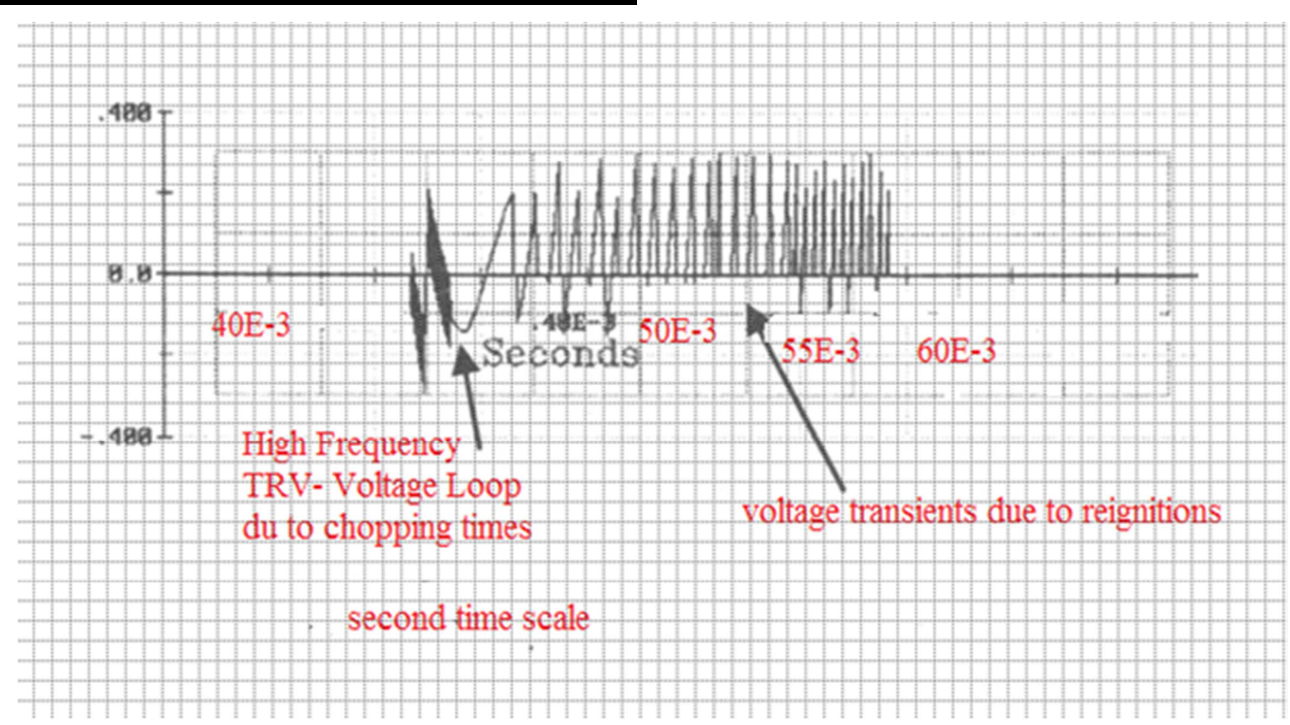

Figure 5. Calculating time of $T R V \&$ Re ignitions.

The figure represents TRV \& Re-ignitions computed in the system when switching off power transformer load that the transient voltage approximately $(350 \mu \mathrm{s}-450 \mu \mathrm{s})$ and shows very high frequency sub transients both going in the negative direction of the voltage -Left side. The second transient ends up in a negative loop of current that changes the polarity to positive at just about $480 \mu$ s time scale indicates in the figure. These two high frequency transients and the voltage loop are associated with the current chop and the immediate re ignition of current. Notice that the negative polarity of the voltage loop and the negative direction of the two high frequency transients agree with the negative polarity of the last cycle of the current interrupted.

\section{Analysis Damping Circuit}

\subsection{Damping Unit: The Vacuum Interrupter Involved on a Very Large Number of Practical Transients Problems in Power System of Medium Voltage Switching Process}

The analysis shows that the effect of damping in an oscillatory circuit can be described in terms of a single parameter, designed $\mathrm{y}$, or its reciprocal $\kappa$, which is the ratio of the resistance to the surge impedance of the circuit:

$$
n=\frac{R}{Z}=\frac{R}{\sqrt{\frac{L}{C}}}
$$


This fact permits the construction of generalized damping curves for different values of $\mathrm{y}$, from which the solutions to many practical problems can be extracted with about the same effort as one expand in using a table logarithms.

Normally our analysis for the switching process basically on parallel $R L C$ circuit as following;

$L=$ Indicative load of stator winding coils

$C=$ parallel parasite 's capacitors - see the introduction

$R=$ evaluating resistance that can be damping oscillating.

$$
L^{-1} * \frac{1}{S^{2}+\frac{S}{T P}+\frac{1}{T^{2}}}=t e^{\frac{-T}{T^{2}}}
$$

From equation (4) express in dimensionless from the current in the inductor of any parallel $R L C$ circuit, with any degree of damping. We note that the only parameter involved is $\eta$. So that a family of generalized curves can be drawn from equation (4) for different values of $\eta$ with dimensionless quantity - $t$, as abscissa. This has been done in Figure.

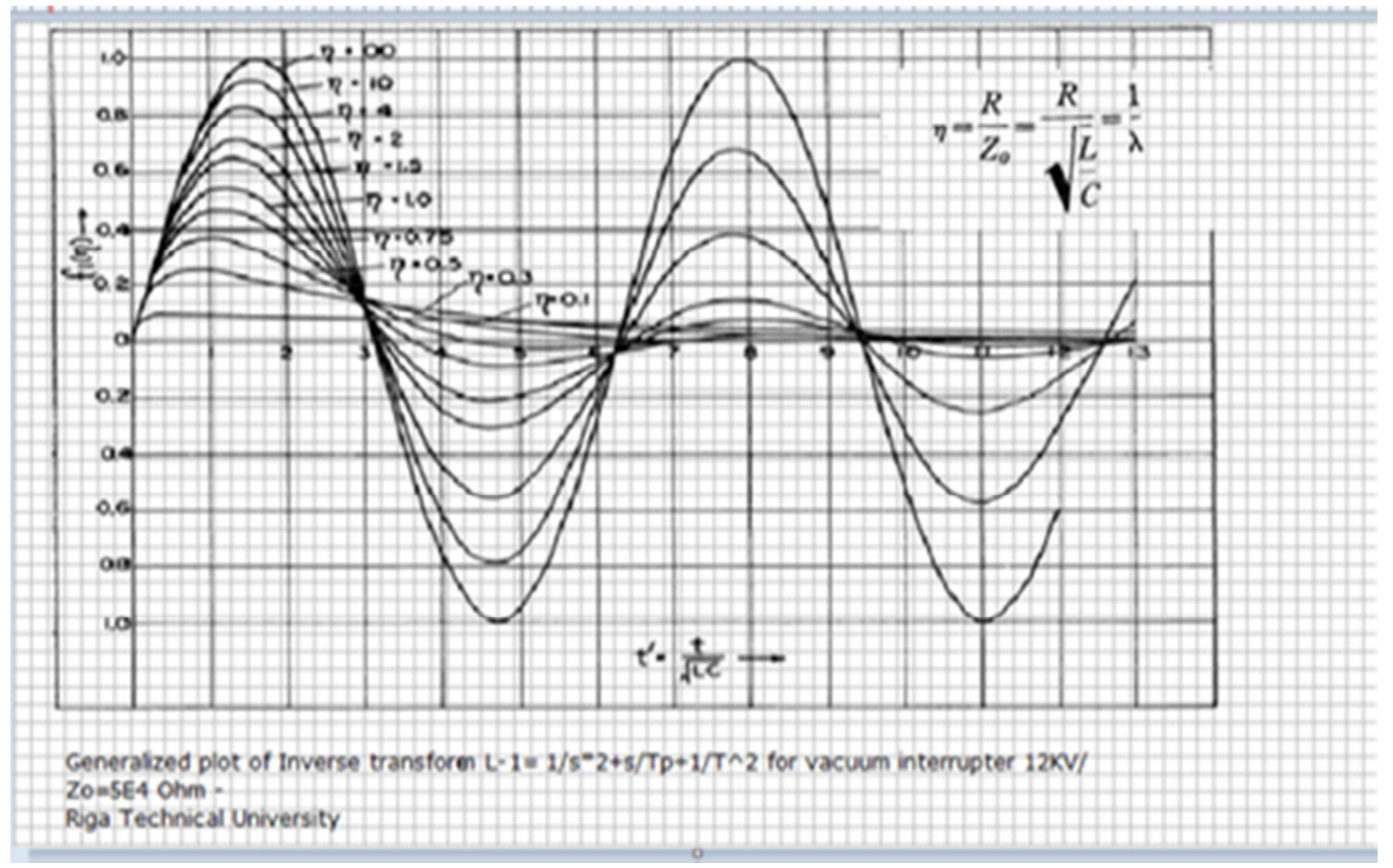

Figure 6. Generalized plot of inverse transform.

Where $\eta=0.5$, the sine function changes from a circular to a hyperbolic function. We might have developed the curves for this condition, following the same argument. By calculating the inductor current in parallel RLC circuit under conditions of a subsidence transient, but have a far wider application. However to gain familiarity with these curves, consider a specific example where the inductor current is required in a circuit in which the components have the following values:

$\mathrm{R}=10^{5} \Omega . \mathrm{L}=5$ Henrys, $\mathrm{C}=2 \times 10^{-8} \mathrm{~F}$.

These values are typical of unloaded transformer, where $R$ represents the equivalent loss resistance. Suppose

$\mathrm{Vo}=13.8 \sqrt{2} \mathrm{KV}$ So. $\mathrm{Zo}=\sqrt{\mathrm{L}} / \mathrm{C}=5 \mathrm{X} 104 \mathrm{ohms}$

$\eta$. $=2$. The curve labelled $\eta=2$ in figure 5 gives the shape of the current we are looking for.

\subsection{Parallel Switching Technique: The Resistor Application Technique R Circuit Will Be Diminished the Amplitude of the First Peak Value Of Chopping Current, If We Connect This Circuit As Parallel Application with Two Electrodes - Parallel Operation Mode}

Further point has also to be consider, namely the frequency $\mathrm{f}(\mathrm{o})$ was measured. The electrostatic charges - static charged - parasitism are almost depleted in the a mount current begin to decrease in the same time of first peak value which generates chopping currents, moreover the formula of the transition processing rate of $d u / d t$ or $d i / d t$ have to be considered.

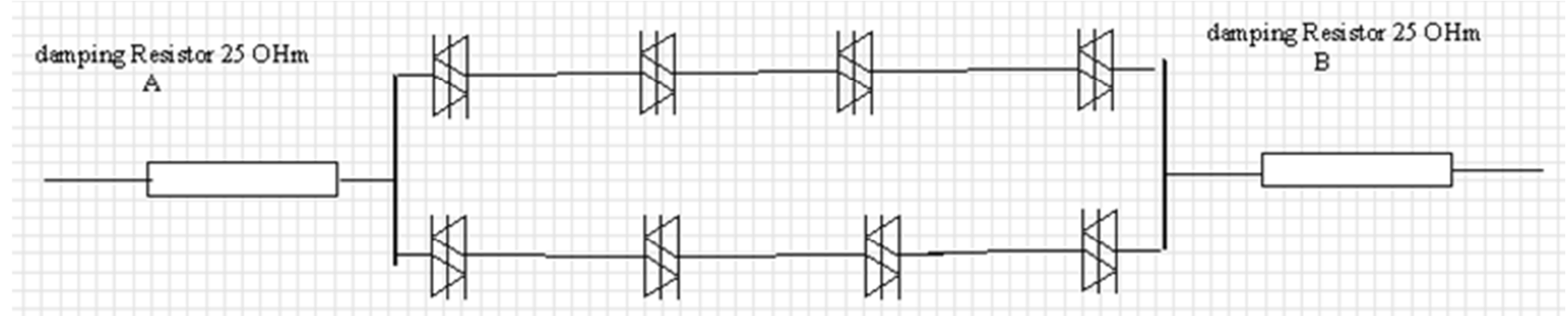

Figure 7. Damping resistors with snubber thyristors circuit. 


\section{Conclusion}

1. The ionization electroplates zone will be evaluated between (20us -250 us) respectively.

2. The real factor for switching transition rating interrupter depends on the values $d u / d t \& d i / d t$ that will be ranging from (700us -1500us) for VD4.

3. Chopping current times (400us-800us).

4. Transient over-voltages (450us -480us-500us).

5. We are still need further modern technology tools for classified the interaction among processing time precisely because matlab /Simulink does not involve for calculating every single step for instance the ionization time or other physical phenomena.

6. The theory of the snubber electronic circuit and other power electronic applications offer more reliable static switching process in the field of medium voltage switching system [16-18].

7. The other processing steps as followings:
a) Chopping current
b) Restrikes voltages
c) Prestrikes voltages
d) Multi reignitions
e) Voltage escalation
f) Post-arc currents
g) NSDD (non- sustained disruptive discharges)

It is often misunderstood how all these phenomena are created and what are their real causes. In brief, the majority of transients associated with vacuum interrupter are not just results of the switching device a lone but the interaction between the device and other components of the power system. In other words, the same vacuum interrupter can cause severe interaction with other power equipment and the problem has to be treated as a whole.

\section{References}

[1] M. T. Glinkowski; "Prediction, modeling, simulation and mitigation of switching transients in vacuum switchgears", ABB Electric System Technology Institute, Raleigh, NC

[2] ECKER G. in LAFFERTY, J. M: "Vacuum arcs- theory application"; Wiley, 1980 p229

[3] M. Mrano, T. Fujii, H. Nishikawa, S. Nishikawa, M. Okawa,"Voltage Escalation in interrupting Inductive Current by vacuum Switches", IEEE Trans on Power Apparatus and Systems. vol. PAS-93, pp. 264-271, 1994

[4] T. Itoh, T. Murai, T. Ohkura, T. Yakami, "Voltage Escalation in the Switching of The Motor Control Circuit by The Vacuum Contactor", IEEE Trans. On Power Apparatus and Systems, vol. PAS-91, pp1897-1903, 1972
[5] J. Panek and K. G. Fehrle, "Over voltage phenomena, Associated with Virtual Current Chopping in Three Phase Circuitd”, IEEE Trans. On Power Apparatus and Systems, vol. PAS-94, pp1317-1325, 1975.

[6] M. Mrano, S. Yanabu, H. Ohashi, H. Ishizuka, T. Okazaki, "Current Chopping Phenomena of Medium Voltage Circuit breakers", IEEE Trans, on On Power Apparatus and Systems, vol. PAS -96, pp143-149, 1977.

[7] F. A. Holmes, "An Empirical Study of Current Chopping by Vacuum Arcs", Paper C74 088-1, IEEE PES Winter Meeting, New York, Jan 1974.

[8] A. N. Greenwood, D. R. Kurtz \& I. C. Sofianek, "A Guide to The Application of Vacuum Circuit Breakers", IEEE Trans. On Power apparatus and Systems, vol. PAS-90, pp1589-1597, 1971.

[9] Y. Murai, T. Nitta, T. Takami and T. Itoh, "Protection of Motor from Switching Surge by Vacuum Switch", IEEE Trans On Power apparatus and Systems, vol. PAS-93, pp1472-1477, 1974.

[10] A. N. Greenwood, "The effect current chopping in circuit breakers on network and Transformers, part II" Trans. AIEEE, vol. 79, PartIII, pp545-555, 1960.

[11] E. J. Tuohy and J. Panek, "Chopping of Transformer Magnetising Currents: part I: Single-Phase Transformere" paper No. F77, IEEE PES Winter, New York, Feb. 1977.

[12] E. W. Buss. R. C. Dugan and P. C. Lyons, "Special Considerations for Mining Operations", IEEE IAS Annual Meeting Conference Record, paper 31-A, pp. 796-775, 1977.

[13] K. Yokkura, S. Masuda, H. Nishikawa, M. Okawa, H. Ohahi, "Multiple Restriking Voltage Effect in a Vacuum Circuit Breaker on Motor Insulation", Paper No. 80SM 697-3, IEEE PES Summer Meeting, Minnesota, 1980.

[14] IEEE Committee Report, "Impulse Voltage Strength of AC Rotating Machines", paper No. 81WM 182-5, IEEEPES winter, Atlanta Georgia 1981.

[15] HARRIS, L. P, "A mathematical model of cathode spot operation" $8^{\text {th }}$ international symposium on Discharges and electrical in vacuum interrupters, Albuquerque, NM, USA1978

[16] Shaker. J. Gatan,"Synchronizing Switching Times of Vacuum Interrupters for Medium Voltage -Switchboards` Techniques, ISBN: 978-1-4673-IEEE 2016 Lodz University- Poland.

[17] Wolf hard Mertz, Monty Grimes, Behlke Power Electronics LLC; "Fast Opining Switch Approach for High-Voltage Vacuum Tube Protection Application" industry Co. DESY, Hamburg Germany.

[18] Susan. E. Childs, Allan. N. Greenwood \& J. S. Sulivan; "Events Associated with Zero current Passage During the Rapid Communication of a Vacuum Arc" IEEE1983. 